\title{
An initial evaluation of cytotoxicity, genotoxicity and antibacterial effectiveness of a disinfection liquid containing silver nanoparticles alone and combined with a glass-ionomer cement and dentin bonding systems
}

\author{
Alicja Porenczuk ${ }^{1, A-D}$, Anna Grzeczkowicz 2,A,B, Izabela Maciejewska ${ }^{3, C-F}$, Marlena Gołaśs,D, Katarzyna Piskorska ${ }^{4, D}$, \\ Adam Kolenda ${ }^{5, C, D}$, Dariusz Gozdowski ${ }^{6, C}$, Ewa Kopeć-Swoboda ${ }^{4, E, F}$, Ludomira Granicka ${ }^{2, E, F}$, Dorota Olczak-Kowalczyk ${ }^{1, E, F}$ \\ ${ }^{1}$ Department of Pediatric Dentistry, Medical University of Warsaw, Poland \\ ${ }^{2}$ The Maciej Nałęcz Institute of Biocybernetics and Biomedical Engineering, Polish Academy of Sciences, Warszawa, Poland \\ ${ }^{3}$ Department of Molecular Medicine, Medical University of Gdańsk, Poland \\ ${ }^{4}$ Department of Medical Microbiology, Medical University of Warsaw, Poland \\ ${ }^{5}$ Department of Prosthetic Dentistry, Medical University of Warsaw, Poland \\ ${ }^{6}$ Department of Experimental Design and Bioinformatics, Faculty of Agriculture and Biology, Warsaw University of Life Sciences, Poland \\ A - research concept and design; B - collection and/or assembly of data; $C$ - data analysis and interpretation; \\ $D$ - writing the article; $E$ - critical revision of the article; $F$ - final approval of the article
}

\begin{abstract}
Address for correspondence
Alicja Porenczuk

E-mail: alicja.mackiewicz@wum.edu.pl
\end{abstract}

Funding sources

Cells isolation procedure was supported by the grant of Ministry of Science and Higher Education NN403 1283/40 PI-IM. The study of antibacterial properties was supported by the grant 1517/PM51D/14, funded by Medical University of Warsaw, Poland.

Conflict of interest

None declared

\section{Acknowledgements}

The authors would like to thank dr inż. Magdalena

Antosiak-Iwańska and Ms Ewa Godlewska

for providing technical support during laboratory work.

Received on January 21, 2016

Reviewed on March 15, 2016

Accepted on July 31, 2017

Published online on July 16, 2018

Cite as

Porenczuk A, Grzeczkowicz A, Maciejewska I, et al. An initial evaluation of cytotoxicity, genotoxicity and antibacterial effectiveness of a disinfection liquid containing silver nanoparticles alone and combined with a glass-ionomer cement and dentin bonding systems. Adv Clin Exp Med. 2019;28(1):75-83. doi:10.17219/acem/76160

DOI

10.17219/acem/76160

Copyright

Copyright by Author(s)

This is an article distributed under the terms of the Creative Commons Attribution Non-Commercial License (http://creativecommons.org/licenses/by-nc-nd/4.0/)

\begin{abstract}
Background. Bacterial reinfection of dental cavities remains an unsolved clinical problem. The search for methods enabling the limitation of the bacterial factor has become the fundamental goal of the dental materials research. Silver nanoparticles (AgNPS) are used as disinfection agents. An incomplete polymerization of the polymer resins combined with AgNPs, along with the increase of the release of the unbound monomers, have been found.
\end{abstract}

Objectives. The aim of this study was to evaluate the vitality of the human dental pulp stem cells (DPSCS) in response to a disinfection agent containing silver and gold nanoparticles (NPS), different bonding systems, glass-ionomer cement (GIC), and their combinations with the disinfection agent. Also, the influence of these materials both on the secretory function of DPSCs and on their antibacterial properties was established.

Material and methods. Cytotoxicity (MTT assay) and genotoxicity (enzyme-linked immunosorbent assay - ELISA) assays were used in the study. Antibacterial features were assessed with the optical density (OD) measurement of the bacteria (Streptococcus mutans, Streptococcus salivarius and Lactobacillus acidophilus) kept in dental materials.

Results. The disinfection liquid proved to be biocompatible. However, it relevantly interfered with the total-etch bonding system in terms of vitality, which may have serious clinical implications. Its combination with the self-etching system was biocompatible, yet it impaired the antibacterial action of the system. An enhancement of antibacterial action of GIC with AgNPs was found.

Conclusions. The disinfection liquid and GIC were biocompatible toward the DPSCs in terms of cytotoxicity and genotoxicity. Simultaneous usage of AgNPs with other dental materials did not affect the biocompatibility of the used materials. The disinfection liquid and GIC acted as antibacterial agents against all studied bacteria species. Used together with GIC and the total-etch bonding system, the disinfection liquid seemed to be efficient toward bacteria, yet it relevantly impaired the antibacterial action of self-etching systems.

Key words: cytotoxicity, silver nanoparticles, glass-ionomer cement, antibacterial properties, adhesives 


\section{Introduction}

Bacterial reinfection of dental cavities, caused by the microgap between the tooth and the filling material, remains an unsolved clinical problem. Therefore, the search for methods enabling the limitation of the bacterial factor has become the fundamental goal of science dealing with dental materials. Recurrent caries development along the edges of the polymer resin fillings can be attributed to the presence of Gram-positive bacteria, such as Streptococcus mutans (S. mutans), so called non-mutans streptococci group, Actinomyces spp. and Lactobacillus spp., in dental plaque. It has been established that caries-associated species possess the ability to survive underneath these restorations for even a few months. ${ }^{1}$ Thus, the application of the dental materials providing bacterial clearance and a proper seal is recommended. Among them, glassionomer cement (GIC) may be chosen due to its remineralizing and antibacterial properties. ${ }^{2}$ The factors defining its usefulness in the cavity restorations include chemical composition (fluoride ions content, their release to and uptake from the surrounding environment) and low $\mathrm{pH}$ during setting. ${ }^{2}$ However, the differences in bacteria susceptibility to fluoride and the strength of the antibacterial action of GIC are still a subject of dispute. Due to its poor physical properties, GIC cannot be considered long-term restoration, so new methods of modifying dental materials with antibacterial agents are being introduced, among them: antibacterial monomers (12-methacryloyloxydodecylpyridinium bromide - MDPB, dimethylamino dodecyl methacrylate - DMADDM and quaternary ammoniummethacrylate - QAMP), inorganic silver compounds (silver nanoparticles - AgNPs) and organic silver compounds (AgNPs bound to oleic acid - Ag-NCs)..$^{3-5}$

The organic matrix of adhesive bonding systems and polymer restorative materials is responsible for their cytotoxicity on pulpal cells. The cytotoxicity of the total-etch bonding systems is very high, as they leak into opened and widened dentinal tubuli after aggressive etching with $32-38 \%$ phosphoric acid. ${ }^{6}$ Furthermore, due to the incomplete polymerization process enhanced by an oxygen inhibition phenomenon, the level of unbound monomer release remains high after curing. ${ }^{6}$ Also, the compatibility of 2-hydroxyethyl methacrylate (HEMA) with water contributes to the degradation of the created bond over time, thus leading to the release of continuous monomers. ${ }^{7}$ This phenomenon is partially eradicated in self-etching bonding systems, the composition of which makes them more compatible with a wetted dentin surface and the collagen matrix. The primer of the self-etching adhesive is acidic in nature and thus acts also as the antibacterial agent. ${ }^{8}$ In order to minimize the cytotoxicity of the bonding systems, a liner is usually administered in deep cavities; however, its application may reduce the adhesion zone and does not always protect the pulp from the bacterial microleakage. There is no stated cavity restoration procedure that would be equally advantageous in all aspects (simultaneous disinfection, proper seal and low cytotoxicity). The usage of either the self-etching bonding systems, total-etch technique and/or antimicrobial agents has to be considered individually.

The clinical utilization of nanoparticles (NPs) and their antibacterial efficiency rely not only on their physicochemical characteristics (sizes, shapes, concentrations of released silver ions), but also on the type of bacteria (species, cell structure, sensitivity). ${ }^{9-12}$ It is known that silver ions are toxic to aquatic organisms even at minor concentrations. ${ }^{13}$ Silver-containing products gradually release cationic silver produced in a redox reaction with water. $^{13}$ The aqueous cellular environment favors this reaction. It remains unknown whether cytotoxicity manifested by the AgNPs results from the silver ions release or from the action of the whole particle. ${ }^{13}$ The scientific research focuses on establishing the features of AgNPs combinations with the polymer resins, which are supposed to broaden the antibacterial range of AgNPs. ${ }^{14-18}$ However, the incomplete polymerization of the polymer resins combined with AgNPs, along with the increase of the release of the unbound monomers, have been pointed out. ${ }^{14}$ Taking all aspects into consideration, the literature does not clearly state if and how AgNPs can be used with the polymer resins in restorative dentistry.

Broad research on the antibacterial properties of AgNPs proved that bacteria do not show or develop drug resistance to them, so their application in dentistry might be particularly advantageous. ${ }^{10,12}$ The level of the released silver ions is determined by the sizes of AgNPs. It was shown that $10 \mathrm{~nm}$ AgNPs freed many active ions, in contrast to larger AgNPs, which released only small amounts of them. ${ }^{19}$ The sizes of AgNPs also determine their surface energy, which decides on their binding to the bacteria surface. ${ }^{10,20}$ The mechanism of action of AgNPs against bacteria is manifested in their interactions with disulphide groups of glycoproteins blocking the bacteria living functions (providing constriction of the synthesis of the cellular wall, nucleic acids and ribosome 30 S-induced proteins). ${ }^{20}$ Furthermore, silver ions destabilize the cellular membrane (by inducing changes of its chemical potential) and reduce the level of intracellular adenosine triphosphate (ATP), the main cellular energy source. ${ }^{21}$ An in vitro study proved that AgNPs act against S. mutans, Streptococcus sobrinus (S. sobrinus) and Lactobacillus acidophilus (L. acidophilus). ${ }^{22}$ Moreover, a suppressive effect of the bacterial biofilm formation on the AgNPs-enriched surface of polymer fillings was detected, which, presumably, may minimize the risk of the recurrent caries incidence. ${ }^{10,17}$

To estimate the influence of silver-containing materials on the dental pulp cells, possible biological drawbacks of their application and their impact on the restorative dental materials, in vitro testing on the dental pulp stem cells (DPSCs) in needed. They are specialized adult stem cells capable of differentiating into a variety of cell types, 
such as odontoblasts, osteoblasts and chondrocytes. ${ }^{23}$ In the mature pulp tissue, the amount of the DPSCs remains stable and the division process is actuated in the case of inflammation or other dangers. ${ }^{23}$ In laboratory conditions, the $9^{\text {th }}$ passage of the DPSCs exhibits properties of an adult odontoblast. ${ }^{24}$ Therefore, DPSCs from the $9^{\text {th }}$ passage and above can be used in laboratory testing of the dental materials without the fear of the disturbances of the results. Differentiated into odontoblasts, the DPSCs secrete dentin building proteins comprising 2 main elements - dentin sialoprotein (DSP) and dentin phosphoprotein (DPP), both encoded by the same dentin sialophosphoprotein gene $(D S P P) .{ }^{24}$

The aim of this study was to evaluate the vitality and secretory function of the DPSCs in response to a disinfection agent containing silver and gold NPs, different bonding systems, GIC and their combinations with the disinfection agent. Antibacterial properties of these materials were also assessed.

\section{Material and methods}

The dental materials (dentin bonding systems, GIC and disinfection liquid with NPs) used in the study are described in Table 1. Short names of the materials used alone and combined with the disinfection liquid are given in Table 2 .

\section{Nanoparticles characteristics}

The evaluation of the internal structure of Nanocare Gold (NG) and its chemical composition was determined in a previous study. ${ }^{25}$ The material comprises various shapes and sizes of NPs suspended in liquid (isopropyl alcohol) and solid (composition unknown) carriers. The material is mainly built of silver (91.34 wt\%) and aluminum (4.53 wt\%). Most of the AgNPs are spherical and $48 \mathrm{~nm}$ in diameter on average. Also, truncated AgNPs sized $125.3 \mathrm{~nm}$ in diameter on average were found. The smallest NP in the sample was $5.8 \mathrm{~nm}$. The data from the physico-chemical analysis revealed that the concentration of AgNPs was $3.96 \mu \mathrm{g} / \mu \mathrm{L}$ (913,400 ppm). Gold was found only in a trace quantity (3.18 wt\%) and was connected to a silver NP providing a conglomerate (Au-AgNP). The cross-section and the chemical analysis revealed that Au-AgNP is a dual particle made of silver as a base with a discoid flake of gold on its surface (silver -56.91 wt\%; gold -33.98 wt $\%) .{ }^{25}$

\section{Cell line}

Human DPSCs from the $11^{\text {th }}$ passage were used in the study. The cells were cultured to over $90 \%$ confluence, washed with calcium- and magnesium-free phosphate-buffered saline (PBS) and trypsinized with $0.25 \%$ trypsin-ethylenediaminetetraacetic acid (EDTA) solution. Afterwards, the DPSCs were seeded in sterile cell culture wells in a concentration of $2 \times 10^{4} / \mathrm{cm}^{2}$. Cell number was estimated using a cell counter (Bürker counting chamber; BRAND GMBH + CO KG, Wertheim, Germany). After $24 \mathrm{~h}$ of incubation, the ex tempore prepared samples of the tested dental materials were added to the cells and incubated for the next $48 \mathrm{~h}$. The negative control were the DPSCs cultured in the medium free from the extracts of the materials.

Table 1. Manufacturers, compositions and applications of the dental materials used in the study

\begin{tabular}{|c|c|c|c|c|}
\hline $\begin{array}{l}\text { Name of the material } \\
\text { (manufacturer) }\end{array}$ & Type of the material & Composition & $\begin{array}{l}\text { Application mode and time } \\
\text { of light curing }\end{array}$ & $\begin{array}{l}\text { LOT } \\
\text { number }\end{array}$ \\
\hline $\begin{array}{l}\text { Clearfil SE Bond }^{\circledR} \\
\text { (Kuraray Medical Inc., } \\
\text { Kurashiki, Japan) }\end{array}$ & $\begin{array}{l}\text { 2-step self-etching } \\
\text { dentin bonding } \\
\text { system }\end{array}$ & $\begin{array}{l}\text { primer: MDP, HEMA, hydrophilic dimethacrylate, } \\
\text { N,N-diethanol-p-toluidine, water } \\
\text { adhesive: MDP, Bis-GMA, HEMA, hydrophobic } \\
\text { dimethacrylate, dl-campherquinone, N,N- } \\
\text { diethanol-p-toluidine, silanated silicate }\end{array}$ & $\begin{array}{l}\text { primer + adhesive application } \\
\text { (drop/cavity) } \\
\text { light curing } 10 \mathrm{~s}\end{array}$ & 41956 \\
\hline $\begin{array}{l}\text { OptiBond Solo Plus } \\
\text { (KerrHawe S.A., Scafati, Italy) }\end{array}$ & $\begin{array}{l}\text { total-etch dentin } \\
\text { bonding system }\end{array}$ & $\begin{array}{l}\text { Bis-GMA, GPDM, HEMA, silica, barium glass, } \\
\text { sodium hexafluorosilicate, ethanol, water }\end{array}$ & $\begin{array}{l}\text { adhesive application } \\
\text { (1 drop/cavity) } \\
\text { light curing } 20 \mathrm{~s}\end{array}$ & 4691988 \\
\hline $\begin{array}{l}\text { Ketac Molar EasyMix }{ }^{\circledR}(3 M \\
\text { ESPE AG, Seefeld, Germany) }\end{array}$ & $\begin{array}{l}\text { glass-ionomer } \\
\text { restorative material }\end{array}$ & $\begin{array}{l}\text { liquid: polycarboxylic acid, tartaric acid, water } \\
\text { powder: calcium, aluminum, silicon fluorosilicate } \\
\text { glass, pigments }\end{array}$ & $\begin{array}{l}\text { powder-liquid } \\
\text { (1 measured portion: } \\
1 \text { drop/cavity) } \\
\text { no light curing, } \\
\text { chemical setting }\end{array}$ & 549021 \\
\hline $\begin{array}{l}\text { Nanocare Gold }{ }^{\circledR} \text { (Dental } \\
\text { Nanotechnology Ltd., } \\
\text { Katowice, Poland) }\end{array}$ & $\begin{array}{l}\text { accessory material } \\
\text { (disinfection } \\
\text { agent) comprised } \\
\text { of silver and gold } \\
\text { nanoparticles }\end{array}$ & $\begin{array}{l}\text { liquid carrier: isoprophyl alcohol } \\
\text { solid carrier: gel-like, unknown composition } \\
\text { silver nanoparticles ( } 91.34 \% \mathrm{MW}) \text {, gold (scarce), } \\
\text { silver-gold nanoparticles ( } 0.03 \% \mathrm{MW})\end{array}$ & $\begin{array}{l}\text { application of the material } \\
\text { (5 drops/cavity, must be left } \\
\text { to evaporate for approx. } 5 \text { min) } \\
\text { no light curing }\end{array}$ & 270213 \\
\hline
\end{tabular}

MDP - 10-methacryloxydecyl dihydrogen phosphate; HEMA - 2-hydroxyethyl methacrylate; Bis-GMA - bisphenol A glycidyl dimethacrylate; GPDM - glycero-phosphate dimethacrylate; MW - molecular weight. 


\section{Sample preparation}

All tested materials were prepared in aseptic conditions in a laminar flow without artificial light and with working forced ventilation, strictly according to the manufacturers' instructions. Nanocare Gold was applied into each sterile well of a sterile 12-well plate in the amount of 5 drops (mean volume of 1 drop: $0.015 \mathrm{~cm}^{3}$; mean density: $0.44 \mathrm{~g} / \mathrm{cm}^{3}$ ) per well and left undisturbed, allowing the carrier to evaporate so as to obtain AgNPs. ${ }^{25}$ The bonding systems were added into the wells (alone and after application of NG) and cured with a diode polymerization lamp Bluephase ${ }^{\circledR}$ Style (Ivoclar Vivadent AG, Schaan, Liechtenstein; power of light $1100 \mathrm{~mW} / \mathrm{cm}^{2}$ ). OptiBond Solo Plus (OB) adhesive was applied in the amount of 1 drop per well (mean volume of 1 drop: $0.032 \mathrm{~cm}^{3}$; mean density: $\left.1.44 \mathrm{~g} / \mathrm{cm}^{3}\right)$; a piece of Clearfil SE Bond (CSE) was prepared according to the manufacturer's instructions by mixing together 1 drop of CSE primer (mean volume of 1 drop: $0.0195 \mathrm{~cm}^{3}$; mean density: $1.18 \mathrm{~g} / \mathrm{cm}^{3}$ ) and 1 drop of CSEadhesive (mean volume of 1 drop: $0.0205 \mathrm{~cm}^{3}$; mean density: $0.99 \mathrm{~g} / \mathrm{cm}^{3}$ ) and applied in the wells in the amount of 1 piece per well. Ketac Molar EasyMix (KM) was hand-mixed and weighted so as to obtain a sample of mean weight $0.10 \mathrm{~g}$ and added to the wells (alone and after the application of NG). RPMI-1640 medium ( $2.5 \mathrm{~mL}$ per vial) was added to each material sample and incubated for $24 \mathrm{~h}$ $\left(37^{\circ} \mathrm{C} ; 5 \% \mathrm{CO}_{2}\right)$. Extract medium was drawn and added to the cells in 1:1 ratio and left for further $48 \mathrm{~h}$. Three replicate wells for each material and their combinations were prepared.

\section{Assessment of cell vitality}

The vitality of the DPSCs was assessed in the MTT assay after 24 and $48 \mathrm{~h}$ of culture. The MTT is a tetrazolium salt that is cleaved to formazan by the succinate dehydrogenase system, which belongs to the cellular mitochondrial respiratory chain. This enzyme is only active in viable cells and reduces the yellow tetrazolium salt into soluble purple formazan. The enzyme activity was measured at $540 \mathrm{~nm}$ in a spectophotometer (Hewlett Packard 8452; Agilent Technologies, Santa Clara, USA). The experiment was carried out in triplicate.

\section{Secretory function of dental pulp stem cells}

The secretory function of the DPSCs was measured using an enzyme-linked immunosorbent assay (ELISA) kit (Uscn Life Sciences Inc., Wuhan, China). DSP and DPP are the 2 odontoblast-specific gene products encoded by a single $D S P P$ gene. Its expression occurs after the formation of a collagenous predentin matrix and is associated with the process of dentinogenesis. The sandwich enzyme immunoassay was used in order to detect the expression of the DSPP gene. The microtiter 96-well plate provided in this kit had been pre-coated with an antibody specific to DSPP. The DPSCs were seeded in a 96-well plate and treated with the extracts of the materials according to the procedure given for the vitality assay. Then, after 24 and $48 \mathrm{~h}$ of incubation, the supernatants were harvested for the cytokine test. The procedure proceeded strictly according to the instructions. The results of the study were obtained using the spectrophotometer at a wavelength of $450 \mathrm{~nm}$ (Hewlett Packard 8452; Agilent Technologies). The negative controls were the wells treated with the cell medium only. The experiment was carried out in triplicate.

\section{Bacteria species}

Standard carious bacteria species $S$. mutans ATCC $^{\circledR}$ $35668^{\mathrm{TM}}$, Streptococcus salivarius (S. salivarius) ATCC ${ }^{\circledR}$ $13419^{\mathrm{TM}}$ and L. acidophilus ATCC ${ }^{\circledR} 314^{\mathrm{TM}}$ (Microbiologics, St. Cloud, USA) were used in the study. The bacteria were incubated in brain heart infusion (BHI) medium in standardized anaerobic conditions $\left(37^{\circ} \mathrm{C}\right)$. The dental materials samples were prepared in test tubes according to the procedures given for the vitality assay, but without the medium addition. Part of the samples (dentin bonding agents) were polymerized with a diode polymerization lamp Bluephase ${ }^{\circledR}$ Style (Table 2).

\section{Bacteria suspension preparation}

The 0.5 (McFarland's density scale) suspensions of $S$. $m u$ tans, S. salivarius and L. acidophilus were prepared. Five $\mathrm{mL}$ of the BHI medium and $400 \mu \mathrm{L}$ of the bacteria suspensions were added to each test tube containing previously applied dental materials. The specimens were kept tightly sealed and incubated for $48 \mathrm{~h}$ in standardized anaerobic conditions $\left(37^{\circ} \mathrm{C}\right)$ with delicate shaking $(100$ rotations $/ \mathrm{min}$; Incu-Shaker Mini; Benchmark Scientific Inc., Sayreville, USA). The negative control were the bacteria in BHI culture medium without the dental materials addition.

\section{Optical density assessment}

The antibacterial properties of the dental materials were assessed by the optical density (OD) measurement of the bacteria kept in the dental materials (polymerized and not polymerized) extracts and the negative controls, and from spectrophotometer read-outs at $500 \mathrm{~nm}$ after $24 \mathrm{~h}$ and $48 \mathrm{~h}$ of incubation.

The bacterial percentage growth inhibition $(\mathrm{IH}(\%))$ was calculated using the formula:

$$
\mathrm{IH}(\%)=\left(\frac{\mathrm{OD}_{\text {contr }}-\mathrm{OD}_{\text {exper }}}{\mathrm{OD}_{\text {contr }}}\right) \times 100
$$

where: $\mathrm{IH}(\%)$ - percentage growth inhibition; $\mathrm{OD}_{\text {contr }}-\mathrm{OD}$ of the negative control; $\mathrm{OD}_{\text {exper }}-\mathrm{OD}$ of the experimental specimens. 
Table 2. Short names of the dental materials used in the study alone and in combination with the disinfection liquid

\begin{tabular}{|c|c|c|c|}
\hline \multicolumn{4}{|c|}{ Dental materials used in the study } \\
\hline \multicolumn{2}{|c|}{ name of the material } & \multicolumn{2}{|c|}{ short name of the material } \\
\hline \multicolumn{2}{|c|}{ Nanocare Gold } & \multicolumn{2}{|c|}{ NG } \\
\hline \multicolumn{2}{|c|}{ Ketac Molar EasyMix } & \multicolumn{2}{|c|}{ KM } \\
\hline \multicolumn{2}{|c|}{ Nanocare Gold/Ketac Molar EasyMix } & \multicolumn{2}{|c|}{ NG/KM } \\
\hline \multicolumn{4}{|c|}{ Dental materials used alone } \\
\hline \multicolumn{2}{|c|}{ polymerized } & \multicolumn{2}{|c|}{ not polymerized } \\
\hline name of the material & short name of the material & name of the material & short name of the material \\
\hline Clearfil SE Bond & CSEs & Clearfil SE Bond & CSEns \\
\hline OptiBond Solo Plus & OBs & OptiBond Solo Plus & OBns \\
\hline \multicolumn{4}{|c|}{ Dental materials used in combinations with the disinfection liquid } \\
\hline \multicolumn{2}{|c|}{ polymerized } & \multicolumn{2}{|c|}{ not polymerized } \\
\hline name of the material & short name of the material & name of the material & short name of the material \\
\hline Nanocare Gold/Clearfil SE Bond & NG/CSES & Nanocare Gold/Clearfil SE Bond & NG/CSEns \\
\hline Nanocare Gold/OptiBond Solo Plus & $\mathrm{NG} / \mathrm{OBs}$ & Nanocare Gold/OptiBond Solo Plus & $\mathrm{NG} / \mathrm{OBns}$ \\
\hline
\end{tabular}

\section{Statistical analysis}

Tukey's honest significance test was conducted at a significance level of 0.05 for all analyses. Pearson's correlation coefficient test was used to examine the relationships between vitality and the expression of the DSPP gene. Data processing was carried out using the statistical software STATISTICA v. 10 (Stat Soft Inc., Tulsa, USA).

\section{Results}

The statistical analyses of the obtained results of the MTT and ELISA assays are presented in Table 3.

Within $48 \mathrm{~h}$, the vitality of cells in the NG group was the same as in the control group.

The comparison between OBs alone and NG/OBs results showed a significantly larger decrease of the vitality of the DPSCs after $48 \mathrm{~h}$ in NG/OBs group ( $\mathrm{p}=0.002)$.

Among all tested materials, the strongest cytotoxicity was observed in CSEs group during the whole observation time. In comparison to the control, both CSEs and NG/CSEs significantly decreased the cells number in both observation periods (CSEs $24 \mathrm{~h}$ $\mathrm{p}<0.001 ; 48 \mathrm{~h} \mathrm{p}=0.006$; NG/CSEs $24 \mathrm{~h}$ $\mathrm{p}<0.001 ; 48 \mathrm{~h} \mathrm{p}=0.022)$. However, we found no differences between CSEs and NG/CSEs groups in terms of the vitality of the cells. Also, the vitality in NG/KM group was indifferent compared to KM alone group and the control group. Nanocare Gold did not cause any increase in the DSPP gene expression level in comparison to the control. In the whole observation time, both OBs and
NG/OBs relevantly raised the $D S P P$ gene expression level in comparison to the control group (OBs $24 \mathrm{~h} \mathrm{p}<0.001$; $48 \mathrm{~h} \mathrm{p}=0.003$; NG/OBs $24 \mathrm{~h} \mathrm{p}<0.001 ; 48 \mathrm{~h} \mathrm{p}=0.001$ ). However, we found no differences in the $D S P P$ gene expression level between these groups. In CSEs group, the Pearson's correlation between ELISA/24 and ELISA/48 was relevantly negative $(r=-1.000)$, which proved a positive correlation between the decrease in the DSPP gene expression level and the vitality of the cells, even though the results of ELISA were indifferent. Comparing CSEs to NG/CSEs, no relevant differences were found. Both KM and NG/KM groups showed no relevance in the results in comparison to the control group or to one another.

To sum up, NG proved to be biocompatible and had no influence on the DSPP gene expression level by DPSCs. In NG/OBs group, a large decrease in the vitality of the cells

Table 3. The statistical analyses of the results obtained for the groups of the materials in MTT assay and enzyme-linked immunosorbent assay (ELISA) in the Tukey's honest test at 0.05 significance level. Descriptive data was presented as mean values and standard deviations (SDS)

\begin{tabular}{|l|c|c|c|c|}
\hline \multirow{2}{*}{$\begin{array}{c}\text { Name } \\
\text { of the } \\
\text { sample }\end{array}$} & MTT/24 & MTT/48 & ELISA/24 & ELISA/48 \\
\cline { 2 - 5 } Control & $0.270(0.017)^{\mathrm{AB}}$ & $0.200(0.091)^{\mathrm{CD}}$ & $0.095(0.008)^{\mathrm{FG}}$ & $0.081(0.005)^{\mathrm{HI}}$ \\
\hline $\mathrm{NG}$ & $0.281(0.053)$ & $0.205(0.055)$ & $0.113(0.023)$ & $0.099(0.023)$ \\
\hline OBs & $0.319(0.049)$ & $0.226(0.083)^{\mathrm{E}}$ & $0.341(0.068)^{\mathrm{F}}$ & $0.174(0.006)^{\mathrm{H}}$ \\
\hline NG/OBs & $0.243(0.037)$ & $0.019(0.019)^{\mathrm{E}}$ & $0.257(0.047)^{\mathrm{G}}$ & $0.189(0.059)^{\prime}$ \\
\hline CSEs & $0.067(0.002)^{\mathrm{A}}$ & $0.014(0.006)^{\mathrm{C}}$ & $0.079(0.007)$ & $0.093(0.004)$ \\
\hline NG/CSEs & $0.077(0.006)^{\mathrm{B}}$ & $0.042(0.028)^{\mathrm{D}}$ & $0.081(0.010)$ & $0.088(0.003)$ \\
\hline KM & $0.300 \mathrm{~b}(0.012)$ & $0.232(0.013)$ & $0.098(0.018)$ & $0.093(0.004)$ \\
\hline NG/KM & $0.326(0.034)$ & $0.264(0.026)$ & $0.090(0.023)$ & $0.085(0.017)$ \\
\hline
\end{tabular}

${ }^{A}$ CSEs vs control, $p<0.001 ;{ }^{B} \mathrm{NG} / C S E s$ vs control, $p<0.001 ;{ }^{C}$ CSEs vs control, $p=0.006$; D NG/CSEs vs control, $p=0.022$; ${ }^{\circ}$ OBs vs NG/OBs, $p=0.002$; ${ }^{\circ}$ OBs vs control, $p<0.001$;

${ }^{G} \mathrm{NG} / \mathrm{OBs}$ vs control, $p<0.001 ;{ }^{\mathrm{H}}$ OBs vs control, $p=0.003 ;{ }^{\prime} \mathrm{NG} / \mathrm{OBs}$ vs control, $\mathrm{p}<0.001$. 
was observed after $48 \mathrm{~h}$. The strongest cytotoxicity was observed in CSEs group during the whole observation time. Addition of NG to CSEs had no impact on its action. Both OBs and NG/OBs relevantly raised the DSPP gene expression level, with no differences between them. The positive correlation between the decrease in the DSPP gene expression and the vitality of the cells was seen in CSEs group. Neither KM nor NG/KM had any impact on the DSPP gene expression level.

The results of the statistical analyses of the bacterial $\mathrm{IH}(\%)$ are presented in Fig. 1-3.

For all bacteria species, the results indicated that both NG and KM relevantly stopped bacteria growth only after $48 \mathrm{~h}$ of incubation (NG - 54.2\%; KM - 53.0\%) (Fig. 1-3). Among all tested materials, NG/KM combination proved to be effective against all bacteria species after $24 \mathrm{~h}$, with the differences between its results and the results of KM (p < 0.001) and NG ( $<<0.001)$ being significant (Fig. 1-3). Yet, after 48 h, there were no differences between these results (Fig. 1-3), apart from S. salivarius group, with the differences between NG/KM and KM still significant ( $\mathrm{p}<0.013$ ) (Fig. 2). Among all tested materials, NG/KM combination seemed to be effective against $S$. salivarius after $24 \mathrm{~h}$, with the differences between its results and the results of KM ( $<<0.001)$, OBs ( $<<0.001)$, CSEs $(p=0.016)$, and NG/CSEs ( $p<0.001$ ) being significant (Fig. 1-3). Yet, after $48 \mathrm{~h}$, there were no differences between these results (Fig. 1-3); NG/OBs inhibited all bacteria growth in all observation periods. However, only for L. acidophilus did NG/OBs cause significant growth decrease after $24 \mathrm{~h}$ compared to OBs group alone ( $\mathrm{p}=0.006)$ (Fig. 3). For other bacteria (S. mutans, S. salivarius), addition of NG to OBs did not have any impact on its action (Fig. 1,2).

The CSEs inhibited all bacteria growth in all observation periods. The results of NG/CSE group showed that adding NG had an influence on the depletion of the antibacterial action of CSEs alone, but the results were significant only between CSEs and NG/CSEs groups toward S. mutans (24 h $\mathrm{p}=0.999 ; 48 \mathrm{~h} \mathrm{p}=676$ ) (Fig. 1). For other bacteria species (S. salivarius and L.acidophilus) in both observation times, addition of NG to CSEs had no relevant impact on its action (Fig. 2,3). Non-polymerized dentin bonding systems manifested no antibacterial activity against $S$. mutans after $24 \mathrm{~h}$ (Fig. 1). Non-polymerized dentin bonding systems, apart from CSEns, manifested no antibacterial activity against S. salivarius and L. acidophilus after $24 \mathrm{~h}$ (Fig. 2,3).

To sum up, the materials NG and KM, used alone, acted as antibacterial agents against all studied bacteria species only after $48 \mathrm{~h}$ of observation. Their connection (NG/KM) seemed to be efficient toward all bacteria species. The combination of NGs with total-etch system (NG/OBs) appeared to be successful against L. acidophilus in the first $24 \mathrm{~h}$. The combination of NG with self-etching system (NG/CSEs) appeared to be unsuccessful against $S$. mutans in a longer observation period (48 h), indicating that it relevantly lowered its antibacterial potential.

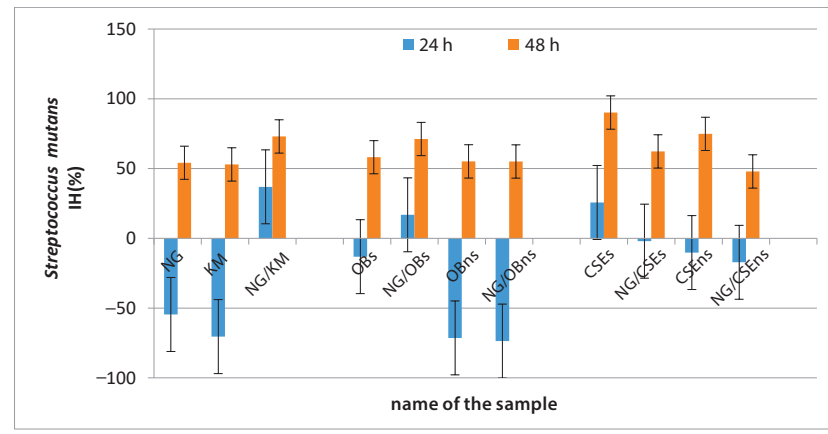

Fig. 1. The percentage growth inhibition $(\mathrm{IH}(\%))$ of Streptococcus mutans by dental materials after $24 \mathrm{~h}$ and $48 \mathrm{~h}$ of observation and the confidence intervals (Cls) based on the multiple Tukey's comparisons

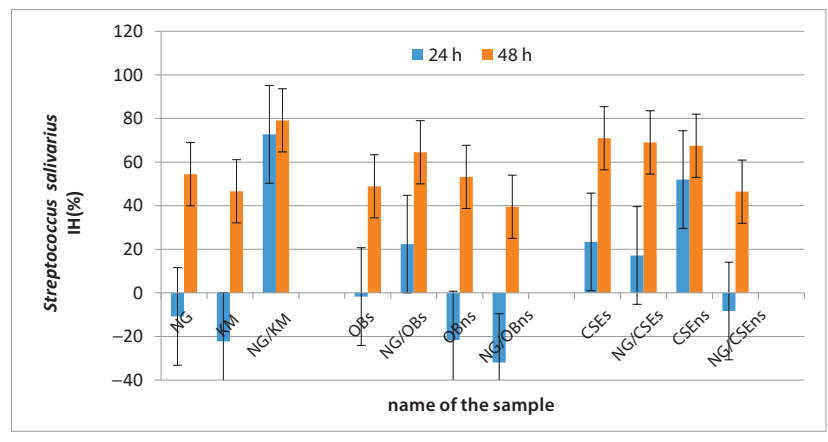

Fig. 2. The percentage growth inhibition $(\mathrm{IH}(\%))$ of Streptococcus salivarius by dental materials after $24 \mathrm{~h}$ and $48 \mathrm{~h}$ of observation and the confidence intervals (Cls) based on the multiple Tukey's comparisons

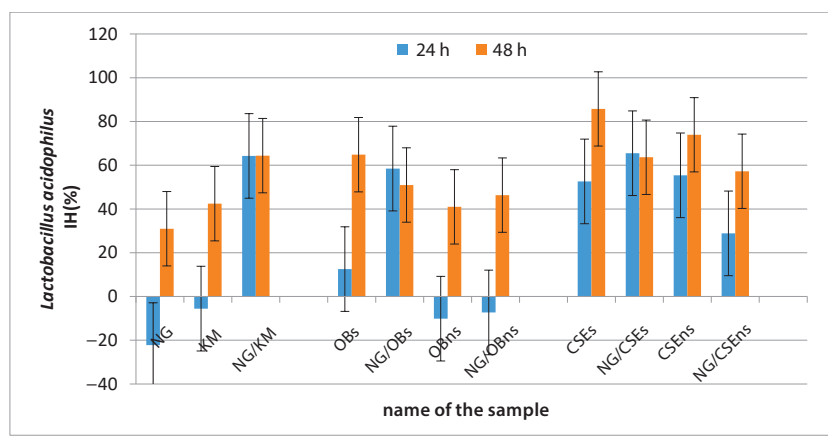

Fig. 3. The percentage growth inhibition $(\mathrm{IH}(\%))$ of Lactobacillus acidophilus by dental materials after $24 \mathrm{~h}$ and $48 \mathrm{~h}$ of observation and the confidence intervals (Cls) based on the multiple Tukey's comparisons

In the non-polymerized materials groups, only CSEns proved to act against $S$. salivarius and L. acidophilus for $24 \mathrm{~h}$.

\section{Discussion}

Research reports indicated that AgNPs cytotoxicity was correlated with such factors as the cell line, the sizes and concentrations of NPs in the examined material, for example, NPs $(1-100 \mathrm{~nm} ; 100 \mu \mathrm{g} / \mu \mathrm{L})$ were highly toxic toward 
NIH3T3 mouse fibroblasts, whereas the same material was biocompatible with human colon carcinoma cells HCT116. ${ }^{26}$ In comparison to other research on the AgNPs cytotoxicity, the data provided from the chemical and microscopic analysis of NG denoted that it would probably be biocompatible with the human pulp cells. ${ }^{25}$ Nevertheless, its impact on polymer resin adhesives remained unknown. Taking different sizes, shapes and dual carriers presence into consideration, we presumed that NG might change other dental materials cytotoxicity level. In a pilot study carried out on human leukemia T lymphocyte cell line, Jurkat determined the cytotoxicity of NG alone and in combination with different adhesives. Even though NG itself proved to be biocompatible with the Jurkat cells, when mixed with polymerized OB or CSE, their cytotoxicity would rise at a statistically relevant level. ${ }^{27}$ We concluded that these results, implying a negative impact of NG on dental adhesives, might be due to the process of NPs agglomeration interfering with the structural elements of the adhesives. This chemical reaction could possibly change the properties of polymer resins in terms of biocompatibility. Therefore, the need for research on the DPSCs arose.

The manufacturer envisaged NG to be used with the total-etch bonding systems, after the dentin etching. In this study, OB was used because it is both widely used in restorative dentistry and more biocompatible with different cell lines in comparison to other total-etch bonding systems due to smaller HEMA release after setting. ${ }^{28}$ We also decided to include a self-etching bonding system in the study protocol. Clearfil SE Bond was thoroughly examined in various research and was proven to be one of the mildest self-etching bonding agents. ${ }^{29}$ Both these materials (OB and CSE) possess similar properties, such as $\mathrm{pH}$, inorganic filler content and the presence of dentin surface wetting components (OB - ethanol; CSE - p-toluidyne) that would not adversely interact with isopropyl alcohol in NG.

The exposition on nanomaterials can occur through direct contact, respiration or digestion. Nanoparticles may relocate from the uptake point via blood or lymphatic vessels and cause multiple side effects, such as chronic inflammation, oxygen stress, thrombosis, and other. ${ }^{11}$ Cellular AgNPs uptake is facilitated by a clathrin-mediated endocytosis and micropinocytosis. ${ }^{11}$ AshaRani et al. proved that the egzocytosis of small NPs $(6-20 \mathrm{~nm})$ is much slower than their uptake, which explains their harmful action against cells. Only 66\% of the collected NPs are excreted from the cells, while the rest groups into larger conglomerates and locates near the cellular membrane and inside the nucleus. ${ }^{11}$ This may lead to the genetic mutations and other cell malfunctions.

Compared to the control group, no differences between the MTT assay results were found in NG group, thus the material was biocompatible with the DPSCs at the early contact stage. Of all tested materials, the lowest cytotoxicity was in KM group, which stays in agreement with other research proceeded on rat stem cells (MDPC-23), where cytotoxicity of KM was the lowest compared to the control group (cellular growth inhibition - 32.5\%; metabolism inhibition - 42.5\%). ${ }^{30}$ The combination of NG with KM was seen as biocompatible up to $48 \mathrm{~h}$. The DSPP gene expression level by the cells in the environment of NG was similar to the control. Based on MTT and ELISA tests, NG may, therefore, be considered biocompatible. Behavior of the DPSCs in terms of the DSPP gene expression level is a result of their primary function, which is the dentin building proteins excretion in response to multiple factors. Through a boosted dentin proteins secretion, the pulpal cells are able to separate from the irritants. Even at a minor AgNPs concentration $(120 \mu \mathrm{g} / \mathrm{mL})$, Miura and Shinohara observed a boosted expression of the repair DNA by HeLa S3 cells. ${ }^{31}$ The scientists have also indicated that the cytotoxicity of silver ions was incomparably higher $\left(\mathrm{IC}_{50}\right.$ - $17 \mu \mathrm{g} / \mathrm{mL}$ ) than of AgNPs $\left(\mathrm{IC}_{50}-92 \mu \mathrm{g} / \mathrm{mL}\right) .{ }^{31}$ For NG, either the concentration of AgNPs or silver ions release may be too low to cause a severe cytotoxic effect or to interfere with the DSPP gene expression level.

Within the dentin bonding systems groups, the cell death was clearly visible in NG/OBs (48 h), which indicates that these combinations of materials may not be clinically acceptable. The comparison between OBs alone and NG/OBs presented OBs as a more biocompatible material to the DPSCs. Both groups relevantly raised the DSPP gene expression level, but with no relevant differences. The largest drop in the vitality of the cells was seen in CSEs and NG/CSEs groups, and the Pearson's test confirmed the correlation between the decrease in the DSPP gene expression level along with the cell death. Due to the fact that NG turned out to be biocompatible, the decrease in the vitality of the cells must, therefore, be linked with the action of the bonding system. On the basis of the MTT test, self-etching system CSE proved to be more cytotoxic than the total-etch system $\mathrm{OB}$, which may result from the methodology of the study. The differences in the vitality of the cells stayed in contrast to an in vitro study conducted by Rathke et al., who proved that CSE released relevantly smaller amounts of HEMA than OB, even after additional etching of the samples. ${ }^{32}$ The possible explanation of our contrary results may lie within the methodology of the study. Both primer and adhesive of CSE were applied in our study, whereas only the adhesive of OB was applied. The etching step was omitted in the protocol. Therefore, on the basis of the obtained results, we may not speculate whether CSE was more or less cytotoxic toward the DPSCs in comparison to OB. Taking only cytotoxicity into consideration, these study results indicate that it may be beneficial to use NG as a disinfection agent, particularly with CSE system, as their combination had no relevant impact neither on the cytotoxicity nor on genotoxicity parameters. In contrast, addition of NG to OB does not seem satisfactory in the clinical practice, mainly because of their impact on the vitality of the cells, which was lower 
in NG/OBs group indicating fast (within first $48 \mathrm{~h}$ ) cell death. This is in agreement with the results of our pilot study, where the combination of NG and OB was also unfavorable toward the Jurkat cells. ${ }^{27}$

A ligand-bound NP is capable of penetrating through the bacterial cell wall, which mechanically damages it and changes its permeability. The AgNPs may lead to the damage of the respiratory chain, as well as to DNA synthesis and cell divisions disorders through their impact on the reactive oxygen species (ROS) formation. ${ }^{10,12,20}$ Liu et al. bound AgNPs to the organic ligand (Ag-NCs) and proved that their antibacterial activity against L. acidophilus was directly proportional to silver concentration. At $50 \mathrm{ppm}$, the bacteria growth inhibition was $57.9 \%$ after $12 \mathrm{~h}$, whereas at $100 \mathrm{ppm}$ it was $66.5 \% .^{3}$ This study was conducted using the same OD technique as in our study. Our results obtained for NG group indicated that the material lacked the immediate antibacterial action. The growth suppression of S. mutans (54.2\%), S. salivarius (54.5\%) and L. acidophilus (31.0\%) was eminent only after $48 \mathrm{~h}$, which may confirm the antibacterial property of the AgNPs composing the disinfection liquid. The differences between our percentage results and those gained by Liu et al. may lie in the amount of silver ions released from AgNPs bound to different ligands. Hernández-Sierra et al. showed that spherical AgNPs of different sizes (25, 80 and $125 \mathrm{~nm}$ ) were capable of inhibiting $S$. mutans growth just at the concentration of $4.86 \pm 2.71 \mu \mathrm{g} / \mu \mathrm{L}$, in contrast to AuNPs of the same sizes and spherical shape, which killed the bacteria only at a high concentration $(197 \mu \mathrm{g} / \mu \mathrm{L}){ }^{33}$ Nanocare Gold is an accessory liquid used for disinfecting cavities after their mechanical preparation. Our own research on its chemical composition revealed that AgNPs were tightly set and had different shapes (mostly spherical), sizes $(5.8-125.3 \mathrm{~nm})$ and the concentration of $3.96 \mu \mathrm{g} / \mu \mathrm{L} .{ }^{25}$ These characteristics suggest mediocre antibacterial potential (large diameters of particles, potentially low silver ions release and low wt $\%$ of gold ions). Heterogeneous sizes and shapes of the AgNPs and the presence of the AuAgNPs conglomerates point out that there are various energy surfaces within the material, which may have an unexpected influence on other dental materials used with it. Due to the small amount of the Au-AgNPs conglomerates in NG, the impact of gold on its antibacterial features may be considered additional to that of AgNPs. Our study results remain in correlation with those obtained by Hernández-Sierra et al. due to the similarities of shapes, sizes and concentration of AgNPs. The efficacy of NG toward different carious-associated bacteria seems surprisingly similar to that of KM. Both materials used separately lowered the bacteria density only after $48 \mathrm{~h}$ of observation, but when used together, they demonstrated to be very powerful in bacteria growth suppression. This combination was also biocompatible with the DPSCs and had no influence on the DSPP gene expression. Łuczaj-Cepowicz et al. proved that KM inhibited the growth of S. salivarius and Streptococcus sanguinis (S. sanguinis) after 7 days, but it had no effect on $S$. mutans. $^{2}$ The researchers emphasized that antibacterial activity of KM was aligned to many factors, including the exact chemical composition, concentration of the released fluoride ions and bacteria sensitivity. ${ }^{2}$ Our study results confirmed the lack of antibacterial potential of KM against S. mutans and S. salivarius, yet when used together with NG, the $\mathrm{IH}(\%)$ of $S$. mutans $(\mathrm{IH}(\%) / 48=73 \%)$ and L. acidophilus $(\mathrm{IH}(\%) / 48=64.4 \%)$ was relevantly higher. In the case of L. acidophilus and S. mutans, addition of NG eminently impaired antibacterial action of CSE, which may have a serious clinical impact. Therefore, their simultaneous usage cannot be considered clinically approvable. In the case of the total-etch bonding system OB, its primary antibacterial power was only slightly suppressed by the addition of the NPs. The results imply that NG boosted action of OB; NG/OBs was particularly competent against $L$. acidophilus $(\mathrm{IH}(\%) / 24=58.5 \%)$.

The polymerization process relies on the monomers cross-linking, an irreversible process that impairs the release of the monomers to the surrounding environment. Studies evaluating the differences in biological behavior of polymerized and not polymerized resins suggested that their antibacterial features were different. ${ }^{34}$ Kim and Shin emphasized that non-polymerized dentin bonding systems performed stronger antibacterial activity than the polymerized ones, which may be explained by the lack of full cross-linking and by undisturbed free monomers release to the environment. ${ }^{34}$ They also pointed out that some of the dentin bonding systems comprising of the antibacterial agents also acted as antibacterial agents after polymerization, but their efficiency was decreased. ${ }^{34}$ Our study data confirms this hypothesis, particularly after $48 \mathrm{~h}$ of observation, where there were no differences between the results gained by the corresponding groups (polymerized and not polymerized).

\section{Conclusions}

The disinfection liquid containing silver and gold NPs and GIC proved to be biocompatible and had no effect on the secretory function of the DPSCs. The studied adhesive systems were cytotoxic and boosted the secretory function of the cells. The addition of the disinfection liquid to the dental materials had no relevant effect on their biocompatibility.

The disinfection liquid as well as the GIC acted as antibacterial agents against all studied bacteria species. The polymerized self-etching bonding system inhibited the bacteria growth. The disinfection liquid used together with the GIC seemed to be efficient toward all bacteria species. Also, its combination with the total-etch system was efficient, but it significantly impaired the antibacterial action of the self-etching bonding system. 


\section{References}

1. Gonzàles-Cabezas C, Li Y, Gregory RL, Stookey GK. Distribution of three cariogenic bacteria in secondary carious lesions around amalgam restorations. Caries Res. 1999;33(5):357-365.

2. Łuczaj-Cepowicz E, Marczuk-Kolada G, Zalewska A, Pawińska M, Leszczyńska K. Antibacterial activity of selected glass ionomer cements. Postepy Hig Med Dosw (Online). 2014;68:23-28.

3. Liu F, Wang R, Shi Y, Jiang X, Sun B, Zhu M. Novel Ag nanocrystals-based dental resin composites with enhanced mechanical and antibacterial properties. Pro Nat Sci-Mater. 2013;23(6):573-578.

4. Zhang K, Cheng L, Wu EJ, Weir MD, Bai Y, Xu HHK. The effect of waterageing on dentine bond strength and anti-biofilm activity of bonding agent containing new monomer dimethylaminododecyl methacrylate. J Dent. 2013;41(6):504-513.

5. Pupo YM, Farago PV, Nadal JM, et al. Effect of a novel quaternary ammonium methacrylate polymer (QAMP) on adhesion and antibacterial properties of dental adhesives. Int J Mol Sci. 2014;15(5): 8998-9015.

6. Kusdemir M, Gunal S, Ozer F, et al. Evaluation of cytotoxic effects of six self-etching adhesives with direct and indirect contact tests. Dent Mater J. 2011;30(6):799-805.

7. Çetingüç A, Ölmez S, Vural N. HEMA diffusion from dentin bonding agents in young and old primary molars in vitro. Dent Mater. 2007; 23(6):302-307.

8. Gondim JO, Duque C, Hebling J, Giro EMA. Influence of human dentine on the antibacterial activity of self-etching adhesive systems against cariogenic bacteria. J Dent. 2008;36(4):241-248.

9. Yen HJ, Hsu SH, Tsai CL. Cytotoxicity and immunological response of gold and silver nanoparticles of different sizes. Small. 2009;5(13): 1553-1561.

10. Pal S, Tak YK, Song JM. Does the antimicrobial activity of silver nanoparticles depend on the shape of the nanoparticle? A study of the Gram-negative bacterium Escherichia coli. Appl Environ Microbiol. 2007:73(6):1712-1720.

11. AshaRani PV, Hande MP, Valiyaveettil S. Anti-proliferative activity of silver nanoparticles. BMC Cell Biol. 2009;10:65. doi: 10.1186/14712121-10-65

12. Prabhu S, Poulose EK. Silver NPs: Mechanism of antimicrobial action, synthesis, medical applications, and toxicity effects. Int Nano Lett. 2012;2:32.

13. Lee YJ, Kim J, Oh J, et al. Ion-release kinetics and ecotoxicity effects of silver nanoparticles. Environ Toxicol Chem. 2012;31(1):155-159.

14. Durner J, Stojanovic M, Urcan E. Influence of silver nano-particles on monomer elution from light-cured composites. Dent Mater. 2011; 27(7):631-636.

15. Krämer N, Möhwald M, Lücker S, et al. Effect of microparticulate silver addition in dental adhesives on secondary caries in vitro. Clin Oral Invest. 2015;19(7):1673-1681.

16. Sokołowski K, Szynkowska MI, Pawlaczyk A, Łukomska-Szymańska M, Sokołowski J. The impact of nanosilver addition on element ions release form light-cured dental composite and compomer into $0.9 \%$ NaCl. Acta Biochim Pol. 2014;61(2):317-323.
17. Zhang $\mathrm{K}$, Cheng $\mathrm{L}$, Imazato $\mathrm{S}$, et al. Effects of dual antibacterial agents MDPB and nano-silver in primer on microcosm biofilm, cytotoxicity and dentine bond properties. J Dent. 2013;41(5):464-474.

18. Sokołowski J, Szynkowska MI, Kleczewska J, et al. Evaluation of resin composites modified with nanogold and nanosilver. Acta Bioeng Biomech. 2014;16(1):51-61.

19. Li Q, Mahendra S, Lyon DY, Brunet L, Li D, Alvarez PJJ. Antimicrobial nanomaterials for water disinfection and microbial control: Potential applications and implications. Water Res. 2008;42(18):4591-4602.

20. Lara HH, Garza-Trevino EN, Ixtepan-Turrent L, Singh DK. Silver NPs are broad-spectrum bactericidal and virucidal compounds. J Nanobiotechnology. 2011;9:30. doi: 10.1186/1477-3155-9-30

21. Dibrov P, Dzioba J, Gosink KK, Hase CC. Chemiosmotic mechanism of antimicrobial activity of $\mathrm{Ag}(+)$ in Vibrio cholerae. Antimicrob Agents Chemother. 2002;46(8):2668-2670.

22. Allaker RP. The use of nanoparticles to control oral biofilm formation. J Dent Res. 2010;89(11):1175-1186.

23. Kacprzyńska E, Maciejewska I. Dental pulp stem cells. Possibilities of application in contemporary dentistry and future directions: Review [in Polish]. Postepy Biologii Komorki. 2011;38(3):467-473.

24. Feng JQ, Luan X, Wallace J, et al. Genomic organization, chromosomal mapping, and promoter analysis of the mouse dentin sialophosphoprotein (Dspp) gene, which codes for both dentin sialoprotein and dentin phosphoprotein. J Biol Chem. 1998;273(16):9457-9464.

25. Mackiewicz A, Olczak-Kowalczyk D. Microscopic evaluation of surface topography and chemical composition of Nanocare Gold. Czas Stomatol. 2014;6(67):826-840.

26. Hsin YH, Chen CF, Huang S, Shih TS, Lai PS, Chueh PJ. The apoptotic effect of nanosilver is mediated by a ROS- and JNK-dependent mechanism involving the mitochondrial pathway in NIH3T3 cells. Toxicol Lett. 2008;179(3):130-139.

27. Mackiewicz A, Grzeczkowicz A, Granicka L, et al. Cytotoxicity of Nanocare Gold ${ }^{\circledR}$ in in vitro assay: A pilot study. Dent Med Probl. 2015;52(2): 167-173.

28. Szep S, Kunkel A, Ronge K, Heidemann D. Cytotoxicity of modern dentin adhesives: In vitro testing on gingival fibroblasts. J Biomed Mater Res. 2002;63(1):53-60.

29. Huang FM, Chang YC. Cytotoxicity of dentine-bonding agents on human pulp cells in vitro. Int Endod J. 2002:35(11):905-909.

30. De Souza Costa CA, Hebling J, Garcia-Godoy F, Hanks CT. In vitro cytotoxicity of five glass-ionomer cements. Biomaterials. 2003;24(21): 3853-3858.

31. Miura N, Shinohara Y. Cytotoxic effect and apoptosis induction by silver nanoparticles in HeLa cells. Biochem Biophys Res Commun. 2009; 390(3):733-737.

32. Rathke A, Alt A, Gambin N, Haller B. Dentin diffusion of HEMA released from etch-and-rinse and self-etch bonding systems. Eur J Oral Sci. 2007;115(6):510-516.

33. Hernández-Sierra JF, Ruiz F, Pena DCC, et al. The antimicrobial sensitivity of Streptococcus mutans to nanoparticles of silver, zinc oxide, and gold. Nanomedicine. 2008;4(3):237-240.

34. Kim SR, Shin DH. Antibacterial effect of self-etching adhesive systems on Streptococcus mutans. Restor Dent Endod. 2014;39(1):32-38. 